
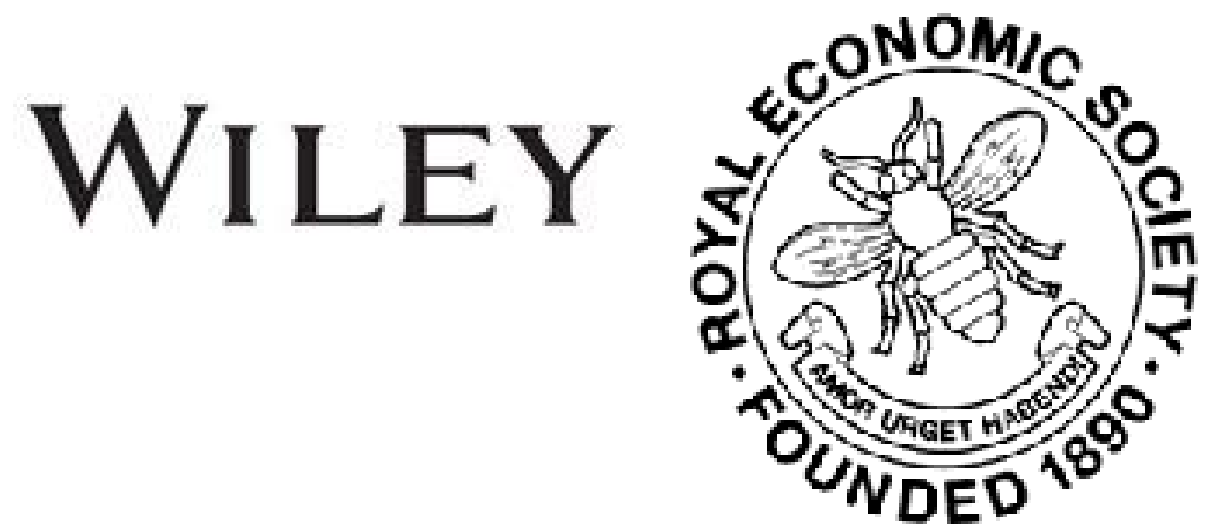

Will the Rating of Land Values Increase Urban Congestion?

Author(s): Edgar Harper

Source: The Economic Journal, Vol. 18, No. 69 (Mar., 1908), pp. 28-41

Published by: Wiley on behalf of the Royal Economic Society

Stable URL: http://www.jstor.org/stable/2221206

Accessed: 27-06-2016 07:07 UTC

Your use of the JSTOR archive indicates your acceptance of the Terms \& Conditions of Use, available at

http://about.jstor.org/terms

JSTOR is a not-for-profit service that helps scholars, researchers, and students discover, use, and build upon a wide range of content in a trusted digital archive. We use information technology and tools to increase productivity and facilitate new forms of scholarship. For more information about JSTOR, please contact support@jstor.org.

Wiley, Royal Economic Society are collaborating with JSTOR to digitize, preserve and extend access to The Economic Journal 


\section{WILL THE RATING OF LAND VALUES INCREASE URBAN CONGESTION?}

Two articles in recent issues of the Economic Journal have been directed to an endeavour to show that the substitution of land value for rateable value as the basis upon which rates are levied would produce an even greater congestion of population in towns than that which now exists. In "The Proposed Relief of Buildings from Local Rates," "Mr. Edwin Cannan says that " the increase of buildings resulting from the change would take place almost entirely, perhaps altogether, in London and the great towns," and that " the new building in the great towns would, of course, deplete the rural districts." Major Darwin follows this up, in his article on "The Taxation of Site Values with Reference to the Distribution of Population," ${ }^{2}$ by arriving at the general conclusions " that land value rating would increase the concentration of our towns about their already congested centres; and that this would be an evil result, which would not be materially lessened by legislation."

There is great satisfaction in coming to a clear issue on this subject, about which there still exists much misapprehension. While concurring in the proposition that congestion is an evil, I entirely deny the other conclusions just quoted. I believe that the premises on which they depend are defective, and that the reasoning by which it is sought to support them is unsound.

To clear the ground, let me say at once that migration from rural to urban districts is an inevitable result of the great development of British manufacturing industries. Also that the tendency of commerce to concentrate in town centres is similarly due to improvements in the methods of exchange, of which London is the most conspicuous example. Both movements will have a certain effect, whatever system of rating is adopted. But there

1 March, 1907.

2 September, 1907. 
is no reason to believe that agriculture will perish in the country, or that concentration need become congestion in the towns.

It is a striking fact that both the writers to whom I have referred fail to examine the relation of the present rating system to these two movements. It has been in operation for three hundred years, and its effects upon urban congestion can easily be traced; whereas the effects of a new system, not yet in operation, cannot be submitted to the test of actual facts.

The present rating system does not charge rates upon all rateable property. All unoccupied property escapes, and various special classes of property are wholly or partially exempt. Moreover, occupied property is only chargeable according to the use made of it. Consequently any owner can escape payment of rates altogether by keeping his property unused, or reduce the charge by restricting the user. Under such a system it is obvious that enterprise and industry must bear an undue proportion of the rates levied, while special facilities are afforded for the restriction of the use of land. The prosperity of a nation depends largely upon the best use being made of its land, whether for industrial, commercial or agricultural purposes. One thing at least is clear : that the present system is in this respect contrary to public policy.

But this is by no means the full extent of the evils involved in the present rating system. The inclusion of buildings and improvements in the basis of charge distributes the burden unfairly between properties that are fully utilised. As a general rule values are highest in the centre of a town, and decrease towards its circumference. But there are many exceptions to that general rule. The task of valuation would be comparatively simple if it were possible to establish any general ratio between the value of real property and its distance from the town centre. Proximity to a railway station, open space or other centre of traffic, frontage to the river or a canal, special local industries, and many other causes have a bearing on the question of value-very often greater than that of the distance from the town centre. And almost everywhere there is a wide difference, even in the same district, between main thoroughfares and side streets in the matter of values.

The important point to bear in mind is that these variations are variations of land value. The value of any particular structure is the same whether it is erected at the town centre or anywhere else, provided it is reasonably suited to its situation. The difference in rental arises entirely from its situation, i.e., from 
site (or land) value. And the range of variation is very wide. To take London as an instance, a square yard of land in the heart of the City is worth at least a thousand times as much as a square yard in the cheapest suburban district. Land value is thus extremely variable, while structural value is constant, or varies only within certain well-defined limits. The quantity of land in a given area can neither be increased nor diminished; whereas structural value can be indefinitely increased. Yet these two values, differing so greatly in their economic characteristics, are amalgamated in one assessment for rating purposes. That anomaly and inequity in the distribution of burden should result is not at all surprising; but the extent to which the distribution of burden is affected is far greater than is commonly supposed. If the addition due to the inclusion of structural value in the assessment bore a fairly constant proportion to the land value, its inclusion would not materially affect the distribution of burden. But the fact is that this proportion varies very considerably. Excluding extreme cases, it may be taken that, in the centre of London, the value of buildings and improvements forms about one-third of the rateable value, while in the suburbs it represents five-sixths. In other words, the inclusion of structural value adds 50 per cent. to land value in the former case, and 500 per cent. in the latter. In the City of London, during the twenty years ending April, 1906, rateable value increased from $£ 3,777,078$ to $£ 5,360,197$, or by $£ 1,583,119$. By far the greater part of this was due to enhanced land value, as the City has long been fully built up, and structural values can be increased only by the substitution of more costly buildings for those previously existing. During the same period the rateable value of the entire County of London (including the City) rose from $£ 30,716,719$ to $£ 43,486,437$. The total increase was thus $£ 12,769,718$; but it is officially estimated that $£ 7,522,302$ was due to new buildings, so that the increase in land value was $£ 5,247,416$. That is to say, that the City, which is only $\frac{1}{12}$ th part of the County in area, enjoyed about one-fourth of the total increase in land values in twenty years. No detailed information exists as to the total land value; but, at any rate, there can be no doubt about the enormous concentration of land values in the centre of London. It is thus evident that rates are levied mainly on land value in the centre, and mainly on structural value in the suburbs. Broadly speaking, the proportion levied on structural value increases with the distance from the town centre, and is greatest at the circumference, i.e., in the very place where building should be en- 
couraged rather than hindered if the development and expansion necessary for public health is to take place.

The great and obvious inequality of burden produced by the present system is only one-and not the most regrettable-of its features. The most disastrous effects arise in connection with the development of land for building and with the standard of house-rent. No builder will erect a house unless there is a reasonable prospect of letting it to a tenant prepared to pay sufficient to cover ground rent, interest on outlay, cost of maintenance, and rates. As the rates average $7 s 6 d$. in the pound in London, they add $37 \frac{1}{2}$ per cent. to the net annual value of land and buildings. The result is that large areas of land, otherwise ready and suitable for building houses, cannot be utilised for that purpose until the pressure of demand adds the requisite $37 \frac{1}{2}$ per cent. to rental values. Moreover, any attempt to secure lower rents by building on cheap land only increases the proportion of rates in respect of structure. The cheaper the land, the greater must be the proportion of structural value included in the assessment. Not many years ago Lord Swaythling (then Sir Samuel Montagu) offered the London County Council 25 acres of land at Edmonton for the erection of workmen's dwellings as a free gift. But notwithstanding the absence of any charge for land, the Council found that the burden of rates upon the projected dwellings was so heavy that any building scheme must involve considerable financial loss.

As may be expected under such conditions, the growth of land value in outlying districts is comparatively slow. Around all our great towns large tracts of land lie practically out of use, or are used for purely temporary purposes, during this so-called period of "ripening for building," which often extends over a whole generation. There is no other similar instance of great and unnecessary delay in the transition of land from one kind of use to another. A very slight alteration in economic conditions will transfer land across the margin of cultivation. When the increase of traffic in a thoroughfare makes it profitable, the houses fronting it are converted into shops without difficulty. Offices, warehouses, and other business premises are always taking the place of old houses, no artificial impediment arising except such as may be due to fag-ends of leases. Only in the change from agriculture to building is the period of transition so long, and the leap in value so enormous. And it cannot be doubted that these results are in the main due to our uneconomic and unequal system of rating.

The restriction thus placed upon building limits the supply of 
houses, while demand increases. The result is an abnormal rise in the standard of rent, squeezing out those in need of houseroom but unable to pay the higher rent. These unhappy persons can only meet the difficulty -if they succeed in meeting it at allin one way, namely, by crowding into a smaller space than is necessary for health and decency. According to the census of 1901, there were in London no less than 304,874 persons living in single-room tenements, and 726,096 persons living under conditions of overcrowding, i.e., more than two persons per room. This is not only a great blot on our civilisation, but a source of national deterioration. It is a most emphatic condemnation of our rating system that it directly and gravely aggravates these disgraceful housing conditions. The growth of manufacture and commerce ought not to be permanently accompanied by poverty and overcrowding; and no system of local taxation should be tolerated which produces such results.

The effects of the unnecessary increase in the standard of rent are not, however, confined to houses. Premises used for manufacture and commerce suffer in the same way. The limitation of the supply of new houses and the high rents they can obtain encourage owners-especially short leaseholders-to keep up old dwellings upon sites that, under a better system, could be devoted to trading purposes, but which, under present conditions, can be profitably let as overcrowded tenements. Thus slums continue to exist, and the abnormally high rent standard is transmitted to industrial and commercial property, the natural extension of which is checked. A particularly unfair extra burden is thrown upon manufacturers using machinery, as the value of all plant which helps to make premises fit for the use to which they are put is included in the assessment.

One important result of the limitation of the area of land available for building, and of the further limitation within that area of the amount available for trade premises, is the erection of lofty buildings. The restrictions imposed on the height of buildings by law prevent the construction of the "sky-scrapers" to be seen in New York; but blocks of dwellings, flats, and offices of five, six, or more storeys are becoming common in the central parts of London. All these developments are abnormal. No one prefers to live in block dwellings or to reach his office by means of a lift; and the fashionable flat, though it has a certain vogue at present, is not the permanent or only home of its occupants. The upper parts of lofty buildings are, therefore, seldom occupied from choice. An interesting light is thrown upon this aspect of 
the question by the experience of the London County Council in displacing population for the formation of the Rotherhithe Tunnel. Required to provide house-room for a number of persons approximating to the number displaced, the Council erected five blocks of dwellings in Rotherhithe, the first being ready for occupation in October, 1902, and the fifth in December, 1904. The rest of the dwelling accommodation within half a mile is afforded by small houses, and an investigation made in June, 1904, showed only 14 vacant tenements in 1,744 of these houses. But the block dwellings have never been fully occupied. The Council's loss of rent due to empty tenements in 1904-5 was nearly 50 per cent.; in 1905-6 it rose to 54 per cent. ; and in 1906-7 it was still as great as 37 per cent. Other instances could be given showing that, wherever population has a choice, low buildings are preferred to those of great height. But notwithstanding this undoubted preference for small houses, there were no less than 143,946 rooms in block dwellings in London in 1906, of which 106,239 were situated in the City and the districts adjacent to it.

In rural districts the existing methods of local taxation, though producing less disastrous results, are quite as unsatisfactory as in the towns. There are the same facilities for the restriction and prevention of the use of land, and the same undue proportion of burden thrown upon its best and most profitable use. The expenditure of the enterprising landlord and the good husbandry of the industrious farmer lead to increased rateable values, and consequently to increased rates. On the other hand, neglected buildings, fences, and ditches, with poor cultivation, bring about deterioration of value and reduced assessments. Since 1894 these conditions have been accentuated by the Agricultural Rates Act, which has increased the rate-burden upon buildings, while the relief given in respect of land is in inverse proportion to the need for it. Being proportioned to the value of the land, it is greatest where land value is highest and the need of assistance smallest, and smallest where land value is lowest and the need for relief most acute. It is the burden of local taxation-not the benefit of exemption - that should be measured by the value of land.

Thus far the argument has proceeded upon lines which can be tested by present-day facts, a few of which have been quoted. It is open to any investigator to examine further by this test all or any of the conclusions which have been reached. Now, however, the theme passes out of the sphere of the actual into that of the probable; for the next step is to inquire what is likely

No. 69.--VOL. XVIII. 
to be the effect of making land values the basis of rating. It should be noticed at the outset that most of the undesirable results predicted by Mr. Cannan and Major Darwin have already arisen under the existing system, and have been gravely aggravated by it. Their arguments, therefore, if sound, amount to this : that the change of basis will increase and intensify the evils caused by the existing system. It is necessary next to consider whether there is any ground for this conclusion.

I should not propose to make the change at a single step. Such a course might lead to an unnecessary dislocation of property values. But it is, nevertheless, far simpler and clearer to conduct the argument by a comparison of the present conditions with those which are probable after the complete change has been made. There are two great alterations involved in the proposal, viz. : (1) the exclusion from assessment of all structural and other improvements, and (2) the levy of the rate upon all land, whether used or not, according to its fair market value between a willing seller and a willing buyer. No doubt, however, it would be found unnecessary to assess land occupied by the community in common, such as roads, public open spaces, \&c.

Commencing, as before, on the margin of the town, where the transition of land from agricultural to building uses is proceeding, the first result of the change will be that the erection of a house upon any particular site will not alter the amount of rates levied in respect of that site as it does at present. When a sufficient number of houses have been built and occupied in the immediate locality, there will be a general but gradual increase in land values there, involving an increase in the yield of the rates; but any such increase must be a trifle compared to that now due to the inclusion of structure in the assessment. In the second place, the amount of the charge for rates in such situations would be very much less than is at present charged upon houses in similar situations. This reduction cannot be accurately estimated, but it might easily exceed 50 per cent. The total annual payment required for a house would therefore be materially less than at present, and this would at once swell the ranks of intending tenants. On the other hand, since all the unused land would be charged according to its fair value, it would no longer be possible to keep it both out of use and out of the market without incurring a loss. The impetus thus given to the building industry would be twofold, as customers would increase in numbers, while more land, and cheaper, would be available for building. Under such circumstances more capital would continue to be attracted to 
building enterprise until the profits on building resumed their normal level, leaving house occupiers with the permanent benefit of more house-room at lower rents.

At the centre, where business premises predominate, the conditions would be affected in a different way. There the bulk of the existing assessments is land value, and there would be no reduction in the amount of rates charged, but rather a tendency to increase it. For although the assessments would be reduced by the exclusion of buildings and machinery, larger poundage must be levied in order to raise the equivalent of the present yield. This, however, will have no effect upon building. As the Separate Report on Urban Rating and Site Values says, " an increased burden will certainly not stop building in the centre of a townit will merely diminish the peculiar advantages of the central position; in other words, it will prevent the site-owner obtaining so much rent." But the erection of trade premises will be indirectly facilitated by the change, inasmuch as the numerous new houses in the suburbs, at low rents, will set free a considerable quantity of centrally situated dwellings-old and often insanitary -for replacement by business premises. Shortly stated, the change will certainly cause an entire local redistribution of the rate-burden. It will be increased in the highly valuable central districts; in a small zone immediately surrounding them the alterations will be slight; while the remaining area-probably three-fourths of the town-will be relieved, the amount of relief increasing with the falling of the land value curve.

While the reduction in rates will reduce the rent standard wherever it occurs, the increase in rates which is probable in the central area will not increase rents there. The new rate will be levied according to land value, and it is unnecessary to repeat the arguments of Adam Smith, Ricardo, and John Stuart Mill, showing that a tax on economic rent falls wholly on the landowner. Rents in the central area would therefore be reduced in two ways : (1) by the new rate, and (2) by the greater quantity of land available for building elsewhere. This result, moreover, coincides with Major Darwin's conclusion "that rent gradients would be rendered less steep by the rating of land values " (p. 338). But it is difficult to understand how this flattening of the rent gradients can have led him to the view that it would produce an inflow of population from the suburbs to the centre. Taking his own illustration of the reservoir with a sinking bed sloping towards the centre, it is clear that if the slope becomes less steep the depth at the centre will be relatively less and the water in the 
reservoir will be more equally distributed, the centripetal tendency being obviously weakened. But gradients are rendered less steep not only by lowering the high end or raising the low one, but also by lengthening the slope. The rating of land values may be expected to do both. The water in the reservoir represents rental value under the existing rating system; and it is not only deepest in the centre, but its expansion is also artificially limited by the strongly-built banks, which may stand for the barrier now blocking the building industry at the town margin. The effect of a process analogous to land value rating will be not only to modify the depth over the fixed area of the reservoir, but also to convert the reservoir itself into a natural basin, the slopes of which, becoming easier the further they extended, would spread the water over a much wider and ever-extending area, thus increasing both the area and capacity of the basin, and providing for an increasing volume of water. The mistake lies in the attempt to compare a growing town with a reservoir of fixed capacity; but Major Darwin's conclusion is further invalidated by the assumption that the rent gradient relates to houses only.

If the increasing rental value of a town is spread over a constantly widening area, it is obvious that population has followed the same course. Population has, in any case, a tendency towards the suburbs, arising partly from the more highly effective demands of commerce and manufacture over house-building for land in the centre, and partly from the desire for purer air and greater space. Notwithstanding the existing barrier at the margin, population shows a continual tendency to move outwards, pushing the barrier before it. Continuing to use London as the largest illustration possible, it may be pointed out that the resident population of the City has fallen steadily ever since 1851 , and is now only about one-fifth of the number at that date. In the central area, made up of the City and immediately adjacent districts, a similar decrease, but smaller in proportion, has been in progress since 1881. But in the outer zone of the Metropolitan Police area the recent decennial increases range between 40 and 50 per cent. And this notwithstanding the block dwellings, insanitary areas and overcrowded houses which abound in the central districts. The outward movement of London population, large as it has been, is yet inadequate to the need for healthy house-room. Its acceleration by the rating of land values is at least a change in the right direction.

I have been unable to find in either article any adequate argument in support of the view that more lofty buildings will be 
erected in town centres as the result of rating land values. Major Darwin says (p. 331) "it would also, as a general rule, on the doctrine of margins, create a tendency for more capital to be expended on a given plot of land"; and again, "any cause tending to increase building in the centre of a town would tend to diminish building in the outskirts"; and he proceeds to indicate, as such cause, the inflow of population to the central districts, as to which it seems clear that he has misapprehended the effect of his own illustration, and that the flow of population will be outwards and not inwards. If this be so, the whole structure of his argument breaks down.

Mr. Cannan apparently (on pp. 42,43) relies on the larger reduction in the rates likely to occur in towns as a basis for the same assumption. His opinion is that the increase of building will be "almost entirely, perhaps altogether, in London and the great towns." As a matter of fact, there will be no reduction in the amount of rates from the change of basis, either in town or country. There will be a large redistribution of the proportions in which the rate-burden is borne by individuals within each rating area; but for actual reductions in the cost of local government ratepayers must still rely upon careful and economical administration. There are two obvious fallacies in this part of Mr. Cannan's argument. First he confuses the reduction of rates in the outskirts of a great town with the reduction of the total amount of the rates borne by the whole town. In the second place, he says that "as population and means are limited, if more of the increase is in great towns, less must necessarily be in small towns and rural districts - that is to say, the increase will be mostly where it adds most to the total cost of construction and maintenance." In other words, Mr. Cannan argues that, because there is more building in the great towns, there must be less in small towns and rural districts. But if the hundreds of thousands of persons now overcrowded in London are enabled to obtain more houseroom at rents within their means, it does not follow that the inhabitants of small towns and rural districts will have to put up with less. The two things have no possible connection. Mr. Cannan appears to base his argument upon the words " as population and means are limited." He seems to assume that if more houses are built in great towns, more people must come from outside to fill them; whereas my contention is that the overcrowded town population will spread into the new buildings. The phrase " means are limited" is vague; but in this connection it appears to mean that if more capital is spent on building 
in London there must be a diminution in the capital so spent in the provinces. It does not require argument to show the fallacy of this conclusion.

The point which has not always been borne in mind is that the central area and middle zone in towns are usually fully built over. In the suburbs, however, there are always considerable areas of land not built on, and any impetus to house building must find its outlet in those localities where vacant sites abound, and not in the central districts. It is not to be imagined that any considerable proportion of houses in the localities already fully built will be increased in height, or pulled down and rebuilt on a larger scale. The principal change will be the substitution of commercial buildings for houses.

Except in the comparatively few cases where the demolition of an unsuitable house would really increase the owner's income by enabling him to realise dormant land value larger than the structural value destroyed, the policy of demolition would be suicidal. The addition of new floors to existing buildings, whether houses or business premises, must in practice be governed by the needs of the present occupiers for space and the ability of existing walls to carry additional weight. The law has wisely instituted a close relation between the height of buildings and the thickness of their walls; and the possibility of extra floors being added to existing buildings is limited.

The effect of the reform will be, in the outskirts where vacant land is cheap and plentiful, to make the cost of premises (rent of land + rent of building + rates) a smaller annual sum than at present. That will increase the demand for premises in the outskirts-not the centre. And in any case it is inconceivable that a reduction in cost in the outskirts should produce its main resulting increase of building in the centre where cost is greatest !

There remains the question whether, in consequence of the facilitation of the development of towns, rural populations will be depleted. This has already been partially considered. It will take a number of years to rearrange the population of the towns. The overcrowded three-quarters of a million in London will not be decently housed within a short space of time. But the freeing of the building industry from its present shackles should ultimately secure an approximation to the desired end. Will the towns then go on to rob the rural districts of their population in greater degree? For it must be remembered that urban poputions, as a rule, increase already at a far greater rate than rural; in fact, the latter may fairly be described as little better than 
stationary. In answer to this question it is safe to say that the rating of land values will not accelerate such a shifting of population. Its effect will be beneficial to rural industry as well as to urban. And in one respect the change will have a wider range in rural districts, namely, in removing restrictions on the use of land. In towns, apart from the idle land ripening for building on the outskirts, land is not frequently held out of use, though the building lease system often preserves old buildings beyond their period of usefulness, and thus prevents for a time the best use of their sites. In rural areas, however, land is not always dealt with on ordinary commercial lines. It is a means of giving dignity, power, and pleasure to its owner, as well as income; and the last item is not always his main consideration. Here in particular the rating of land values will come to the assistance of agriculture. Mr. Cannan says " you cannot encourage a farmer to enlarge his farmhouse by promising to free him from rates for dust collection." No! but by actually freeing buildings and other improvements from all rates, you will certainly make it easier and cheaper for him to improve not only his farmhouse, but his steadings also; and thus will be set up a greater attraction for capital to be invested in agriculture. Nor is this all. In those unfortunately rather numerous cases, where the interest on the outlay on buildings and improvements swallows up the whole of the rent, it is clear that the land value is nil ; and all such farms -while these conditions prevail-will escape rates. I have little doubt, however, that the impetus given to agriculture by the change will speedily produce some land value, even in such cases. The important point, however, is that the rates will be levied according to the land value, and thus relief will automatically be given to poor farms in the proportion in which it is needed. Moreover, it is unlikely, under the new régime, that we shall hear much more of the inability to obtain land for allotments and small holdings. Under all these circumstances there is no reasonable doubt that more labour and more capital will be attracted to agriculture; and, on the whole, I am inclined to believe that the rural population will tend to increase under the proposed system, and will be able to resist the magnetic town influence not less effectively than at present, but more.

I have already referred to the failure of both articles now under discussion to consider the effects of the present rating system upon the problem of congestion. It is, however, only fair to say that Mr. Cannan came very near starting on this line of examination, but unfortunately discarded it after arriving, upon insufficient 
grounds, at the conclusion that "the rating of buildings is a means for making people pay in proportion to what they get." The student of rating problems is much indebted to Mr. Cannan for the emphasis he has laid on the fact that rates for local administration are in the nature of payment for services rendered. This is exactly true of the total amount collected in any given rating area for the purely local services administered in that area.

But Mr. Cannan assumes that the same statement holds good with regard to the individual ratepayer. Even were it so, the rates for national services, such as poor relief and education, are exceptions to the doctrine, which thus leaves half the problem untouched. But the assumption will not bear examination. It is twofold : (1) " that the addition of buildings to bare land increases the expenses of the local authority, and (2) that the increase is greater the greater the value of the building of any particular class, no matter whether the increase of expense is in exactly the same or in a somewhat greater or smaller proportion than the increase of value" (p. 39). The form in which it is stated indicates that Mr. Cannan is himself aware of the weakness of this position, for he practically admits that no ratio can be established either between the value of the building and the increase in local expenditure, or between different classes of buildings. These admissions alone suffice to vitiate the attempt to prove a direct relation between building values and local expenditure; and, as a matter of fact, the variations are considerable. For instance, new buildings do not add to the expenses of the local authority in making new roads, as this cost is borne by the frontage owners. Again, shops do not add to those expenses in the matter of street lighting, as in providing their own light they also illuminate the street. The public lamps maintained by the local authority become really necessary to the general public only when the shops are closed and do not require them. If, however, everything that adds to the expenses of the local authority is on that account to become a basis of charge for rates, we shall soon get back to the days of the octroi and the poll-tax.

The principle of rating for local beneficial services lies in measuring the charge for them according to the benefit enjoyed by each ratepayer; and this is just what the values of individual buildings fail to do. Take the service of drainage as an instance. When a drainage system is laid out by a local authority the benefit is distributed over the district it serves, whether built on or not. The owner of vacant land can obtain a higher price or ground rent for it because there is a drainage system; and this benefit comes to him irrespective of the erection of the buildings. 
Similar reasoning applies to the maintenance, lighting and cleansing of streets, and all other local services. In short, the benefits accruing from all beneficial services, although they are enjoyed by the occupier, take permanent and pecuniary shape only in the payment of rent for the use of the site made by the occupier, either directly or indirectly, to the landowner. Thus they invariably tend to enhance land value, which is clearly indicated as a much better measure of payment according to benefit than buildings. In view of this conclusion, it is unnecessary to follow up in detail the criticism of the new policy as being one of subsidising buildings. Local expenditure may perhaps be not unfairly termed a subsidy in aid of land values; but it does not add a sixpence to building values.

I have not attempted to follow Major Darwin into the wide field embraced by the doctrines of incidence. On the broad issue that the inclusion of buildings with land in a single assessment unduly burdens the outskirts of a town and unfairly benefits the centre, the exact proportion in which the unequal charge is divided between owner and occupier is of distinctly minor importance. If our local rates are levied in such a manner as seriously to hinder building, restrict the growth of towns, hamper commerce and industry, penalise enterprise, reward neglect, and produce racedecay through inadequate house accommodation, these facts are surely sufficient to condemn the system. It grew up-or, as Mr. Cannan says, "established itself" - on the basis of a law now three hundred years old, which provided that the poor should be relieved by the taxation of every inhabitant and every occupier in the parish. Its existence has throughout been marked by struggles between rating authority and ratepayer-Parliament occasionally intervening - to define a reasonable basis upon which inhabitants and occupiers should pay; and there are numerous points of this kind which to-day still require adjustment. During the nineteenth century, with an enormous increase of structural and other improvement values, and extreme variations of land value produced by the growth of towns, it has become quite unsuited to the economic conditions of this country. The time has arrived when its place should be taken by a simple system with a scientifio basis.

EDGAR HARPER 